\title{
Fatigue and bending behaviour of friction stir welded DH36 steel
}

\author{
Steven Fowler · Athanasios Toumpis ${ }^{*} \cdot$ Alexander Galloway
}

Department of Mechanical \& Aerospace Engineering, University of Strathclyde; James Weir Building, 75 Montrose Street, Glasgow, G1 1XJ, United Kingdom

\begin{abstract}
Friction stir welding presents many advantages over conventional welding techniques; however, there is limited published data with regards to the fatigue and bending performance of friction stir welded steels. Hence, this investigation aims to evaluate friction stir welded DH36 steel subjected to these loading conditions. A comprehensive fatigue and bending programme has been implemented to assess the impact of process related features, such as weld root flaws, on the welds' performance. Strain gauges located on the top and bottom surfaces of fatigue samples allowed the secondary bending stresses to be quantified when clamped in the fatigue test machine. Bend test samples were completed to a $180^{\circ} \mathrm{U}$ bend for as-welded and ground samples. The bend testing programme demonstrated satisfactory performance of friction stir welded DH36 steel. Despite the presence of surface flaws, cracks did not propagate in bending indicating adequate levels of toughness. Fatigue performance was poor in comparison with results from similar welds however, it was found to be acceptable in terms of class recommendations for fusion welding. This lower performance was predominantly attributed to a weld root flaw. Strain gauge measurements indicated that the local stress at the weld root was up to $25 \%$ lower than the nominal stress determined prior to testing, thus artificially improving fatigue performance. Welds of good quality and refined microstructure were found, however process related flaws on the top and bottom surface emphasise the need for optimisation of the tool material and welding parameters.
\end{abstract}

Keywords Friction stir welding; Low alloy steel; Mechanical testing; Fatigue; Bend testing; Microstructure

* Corresponding author. $\quad$ Tel: +44 01415745075

E-mail address: athanasios.toumpis@ strath.ac.uk 


\section{Introduction}

Friction stir welding (FSW) has been extensively used on softer metals such as aluminium and magnesium alloys [1-4]. However, recent advances in tool materials have made this process applicable to steel. FSW offers many advantages over conventional fusion welding techniques. One publication [5] determined that the lower heat input associated with FSW minimises the grain growth in the heat affected zone (HAZ), which tends to be an issue in welded materials. As FSW is a solid state process, additional problems such as porosity, slag inclusions and hydrogen cracking are also eradicated [5].

McPherson et al. [6] carried out a direct comparison between FSW and submerged arc welded (SAW) DH36 steel. This study was performed with $4 \mathrm{~mm}, 6 \mathrm{~mm}$ and $8 \mathrm{~mm}$ thick plates. Distortion in the FSW plates was found to be less than SAW although there was still significant distortion in the $4 \mathrm{~mm}$ FSW plate. The impact toughness at $-20^{\circ} \mathrm{C}$ was similar in both types of weld but more uniform in the FSW samples. Fatigue testing indicated superior performance of the FSW specimens.

A comprehensive study [7] was undertaken which investigated the effect of welding parameters on the fatigue performance of $6 \mathrm{~mm}$ thick FSW DH36 steel. This research determined that fatigue performance improved as the traverse speed decreased. Two of the 'slow' weld specimens were found to reach over $2.6 \cdot 10^{6}$ cycles while 'fast' test specimens failed between $2 \cdot 10^{5}$ and $7 \cdot 10^{5}$ cycles. An intermittent weld root flaw was also documented, subsequently reducing fatigue performance. Root flaws are cracks formed by insufficient penetration of the FSW tool. The 'intermediate' traverse speed weld exhibited a heterogeneous microstructure which included ferrite grains of random geometry and acicular shaped bainite. The same authors [8] indicated that the weld's mechanical properties are not substantially affected by the heterogeneity of the microstructure. Fatigue performance of defect free FSW GL-AH36 shipbuilding steel was found to be similar and in some cases better than the base metal [9]. These welds were deemed to show very good mechanical properties.

Dickerson \& Przydatek [10] investigated the impact that weld root flaws have on the fatigue and bending performance of various FSW aluminium grades. This work is applicable to FSW of steel with regard to process related flaws. The research showed that root flaws were detrimental in terms of fatigue and bending by aiding crack growth throughout the weld. It was noted that weld root flaws below a length of $0.35 \mathrm{~mm}$ had very little impact on the fatigue performance; however, flaws above this value were detrimental to fatigue life. Following this, Kadlec et al. [11] found the critical length to be $0.30 \mathrm{~mm}$ in AA7475-T7351 aluminium alloy therefore drawing similar conclusions. Additional research [12] also highlighted the negative effect of the weld root flaw on fatigue performance of FSW 2024-T3 aluminium alloys.

In terms of fatigue performance, a separate research [13] determined that the fatigue crack growth resistance was greater in the weld region than the parent material (PM) in FSW AISI 409M ferritic stainless steel. This was directly correlated to the dual phase ferritic-martensitic microstructure in comparison with the single phase ferritic microstructure of the base metal. Pandey et al. [14] documented similar results with regards to fatigue crack growth resistance. 
Mahoney et al. [15] reported that FSW X42 carbon steel passed numerous root bend tests. It was noted that full penetration of the tool was achieved thus no root flaws existed. Thomas et al. [16] carried out bend testing on double sided FSW low carbon steel grade BS970 and chromium alloy steel of grade DIN 1.4003. All were found to bend successfully to $180^{\circ}$ and were comparable to the equivalent parent material. No obvious flaws were noted in the microstructure of the welded region.

Allart et al. [17] observed a Widmanstätten ferritic-pearlite structure in the thermomechanically affected zone (TMAZ) for FSW DH36 steel. No bainite transformation was found in the weld nugget which coincided with a maximum hardness measurement of $260 \mathrm{HV}$ at the top of the TMAZ. Reynolds et al. [18] reported martensite formation as well as bainite in the stir zone for a traverse speed of $456 \mathrm{~mm} / \mathrm{min}$. An additional publication [19] found that surface oxides are dispersed through the weld material through local plastic deformation.

In the present study, the behaviour of $6 \mathrm{~mm}$ thick FSW DH36 steel is examined in fatigue and bending. The impact of process related flaws in mechanical testing is also investigated. Strain gauges were fitted to fatigue samples to quantify the secondary bending stresses during clamping in the fatigue test machine. The weld microstructure was also assessed to determine the influence of possible flaws on the weldment's mechanical properties.

\section{Experimental procedure}

\subsection{Materials and processes}

Low alloy steel grade DH36 of $6 \mathrm{~mm}$ thickness with the nominal chemical composition which is presented in Table 1 was investigated in this study. Each plate had dimensions of $2000 \mathrm{x}$ $200 \mathrm{~mm}$ and was welded in the as-received condition, i.e. without any prior surface preparation. A MegaStir Q70 pcBN FSW tool for steel (70\% pcBN - 30\% WRe binder) with a scrolled shoulder and stepped spiral probe (length $5.7 \mathrm{~mm}$ ) was employed to join the plates at a traverse and rotational speed of $300 \mathrm{~mm} / \mathrm{min}$ and $400 \mathrm{rpm}$ respectively. Welding was performed in position control (i.e. the utilised PowerStir welding machine was instructed to maintain constant distance from a given datum point irrespective of the forces acting upon the welding head) without preheating of the tool. The FSW tool rotated counter clockwise, with $0^{\circ}$ tool tilt, in an inert gas environment to protect it from high temperature oxidation; a drawing of the exact same tool has been disclosed in a previous work [8].

Table 1 Chemical composition of $6 \mathrm{~mm}$ thick DH36 steel (wt.\%)

\begin{tabular}{cccccccc}
\hline $\mathrm{C}$ & $\mathrm{Si}$ & $\mathrm{Mn}$ & $\mathrm{P}$ & $\mathrm{S}$ & $\mathrm{Al}$ & $\mathrm{Nb}$ & $\mathrm{N}$ \\
\hline 0.11 & 0.37 & 1.48 & 0.014 & 0.004 & 0.02 & 0.02 & 0.002 \\
\hline
\end{tabular}

\subsection{Microstructural evaluation and micro-hardness testing}

Metallographic examination of the weld was carried out in order to, firstly, characterise the microstructure of the weld and secondly, to correlate the failure mechanisms in fatigue and 
bend testing to microstructural flaws or defects. Hardness measurements were recorded using a Vickers micro-hardness tester on etched microstructural samples and by applying a load of $200 \mathrm{gf}$, therefore allowing the hardness distribution of the weld to be plotted and analysed.

\subsection{Tensile testing}

The specimen geometry for both tensile and fatigue testing conformed to the relevant ISO standards [20, 21]. The sample preparation adhered to the detail specified in BS 7270 [21]; this included machining, grinding and polishing the sides to a minimum of $0.2 \mu \mathrm{m} R_{a}$ (arithmetical mean deviation of the profile). Three tensile tests were performed on an Instron 8802 fatigue testing machine in order to determine the yield strength of the material.

\subsection{Fatigue testing}

The sample geometry, preparation and testing machine used for fatigue testing was consistent with the details stated in Section 2.3. A total of twelve as-welded specimens were examined under fatigue testing conditions. The two stress ranges which were used and the corresponding test details are summarised in Table 2.

Table 2 Stress ranges and details of fatigue testing

\begin{tabular}{ccccccc}
\hline $\begin{array}{c}\text { of } \\
\text { Yield }\end{array}$ & $\begin{array}{c}\text { Number of } \\
\text { Specimens } \\
\text { Tested }\end{array}$ & $\begin{array}{c}\text { Stress } \\
\text { Range, } \\
\Delta \sigma \\
(\mathrm{MPa})\end{array}$ & $\begin{array}{c}\text { Maximum } \\
\text { Stress, } \sigma_{\max } \\
(\mathrm{MPa})\end{array}$ & $\begin{array}{c}\text { Minimum } \\
\text { Stress, } \\
\sigma_{\min }(\mathrm{MPa})\end{array}$ & $\begin{array}{c}\text { Mean } \\
\text { Stress, } \\
\sigma_{\mathrm{m}} \\
(\mathrm{MPa})\end{array}$ & $\begin{array}{c}\text { Stress } \\
\text { Amplitude, } \\
\sigma_{\mathrm{a}}(\mathrm{MPa})\end{array}$ \\
\hline 70 & 6 & 254.7 & 283.0 & 28.30 & 155.7 & 127.4 \\
80 & 6 & 291.1 & 323.5 & 32.35 & 177.9 & 145.6 \\
\hline
\end{tabular}

\subsection{Secondary bending measurements}

Strain gauges were fitted on five of the fatigue samples in order to quantify the secondary bending stresses induced by clamping them in the fatigue testing machine. This allowed a comparison between the nominal stress range determined prior to testing and the local stress on the top and bottom surfaces. The strain gauges were fitted $30 \mathrm{~mm}$ from the centre of the weld on the advancing (AD) and retreating (RT) side, top and bottom, as illustrated in Fig. 1. 


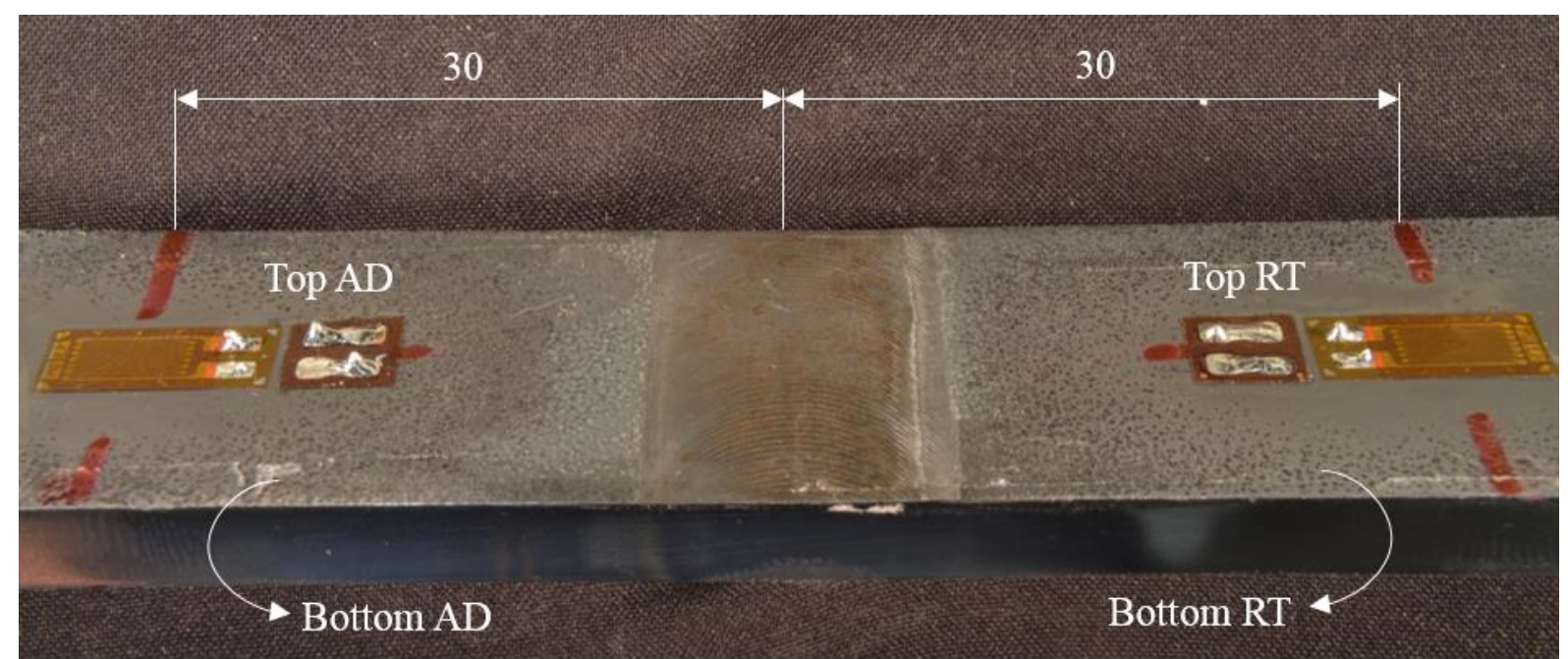

Fig. 1 Strain gauge positioning on fatigue specimens

\subsection{Bend testing}

The geometry of the bend test specimens conformed to ISO standards [22]. The final specimen was a $26 \times 200 \times 6 \mathrm{~mm}$ rectangular strip. The former diameter and distance between the rollers were calculated as $25.4 \mathrm{~mm}$ and $42 \mathrm{~mm}$ respectively. A schematic of the bend testing jig is depicted in Fig. 2 for a root bend.

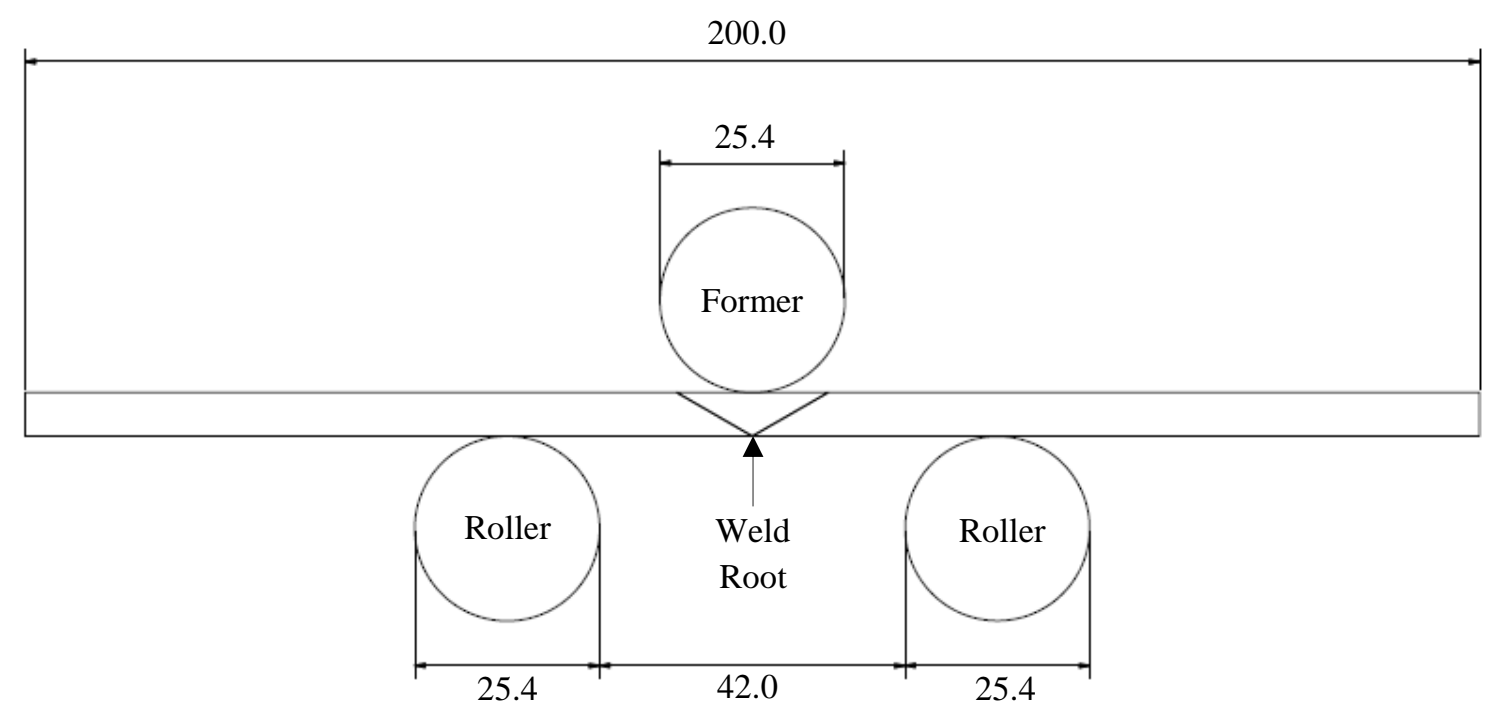

Fig. 2 Bend test jig setup (dimensions in $\mathrm{mm}$ )

Bend tests were completed as $180^{\circ} \mathrm{U}$-bends; the testing programme was as follows:

- 3 root bends in the as-welded condition

- 3 face bends in the as-welded condition

- 3 root bends with top and bottom surfaces ground off

- 3 face bends with top and bottom surfaces ground off 
Six samples were ground to remove process related surface flaws thus directly testing the weld material.

\section{Results}

\subsection{Microstructural characterisation}

\subsubsection{Weld microstructure}

Fig. 3 presents a typical macrograph of the steel friction stir weld. The microstructural images presented in Fig. 4 correlate with the annotations in this macrograph and are representative of the entire welded plate. It should be specified that all images presented in this study show the AD side on the left.

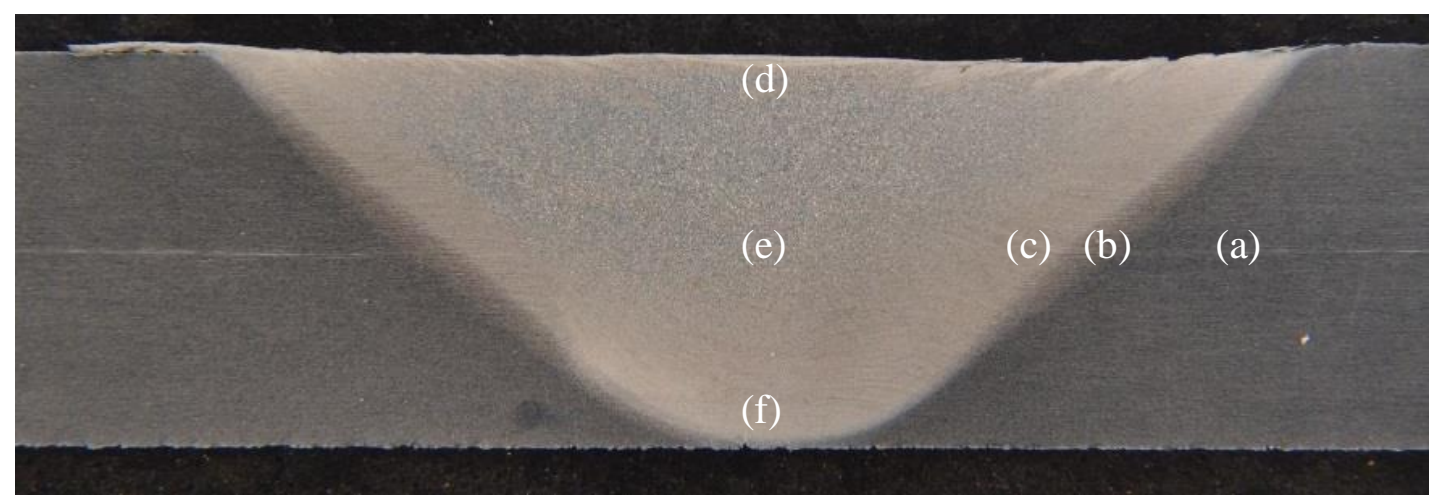

Fig. 3 Macrograph of FSW cross-section highlighting critical regions for examination

Fig. 4a depicts the PM DH36 steel where a banded ferrite and pearlite microstructure is observed. The HAZ pictured in Fig. 4b contains ferrite grains of approximately the same size as the PM; yet, the heat input has caused the pearlite to partially degenerate. The comparable grain size of the HAZ and PM indicates that the heat input has not caused significant grain growth. This can be an area of concern in fusion welded structures and is a clear advantage of FSW over typical fusion welds [5].

There is substantial grain refinement on the boundary of the TMAZ due to thermo-mechanical processing [6]. This region, illustrated in Fig. 4c, exhibits a homogeneous microstructure consisting of acicular-shaped ferrite grains along with finer ferrite grains of random geometry. The centre of the TMAZ is depicted in Fig. 4d. The microstructure is found to be heterogeneous, consisting of acicular-shaped ferrite, ferrite regions of random geometry and acicular shaped bainitic ferrite. The formation of bainite raises the yield strength however, ductility is reduced. This type of microstructure lies in between the 'intermediate' and 'fast' welds documented in a previous publication [7]. However no martensite formation was reported as in prior research [8].

A band spreading across the top of the weld (for a depth of $0.3 \mathrm{~mm}$ ) differed from the main TMAZ microstructure. Fig. 4e depicts the transition between this band and the centre of the TMAZ. A homogeneous microstructure of randomly shaped fine ferrite grains exists in this section of the weld. The stirring process induces heat into the stir zone; therefore, there is minor indication of decarburisation at the top surface which prevents bainite formation. Fig. 
4f illustrates a similar grain structure to that of the top surface. This is located near the weld root where the temperature during welding is at its lowest [8]. Lower temperatures inhibit the formation of bainite due to slower cooling rates however, this region is still mechanically stirred hence the ferrite grains are smaller than the PM.

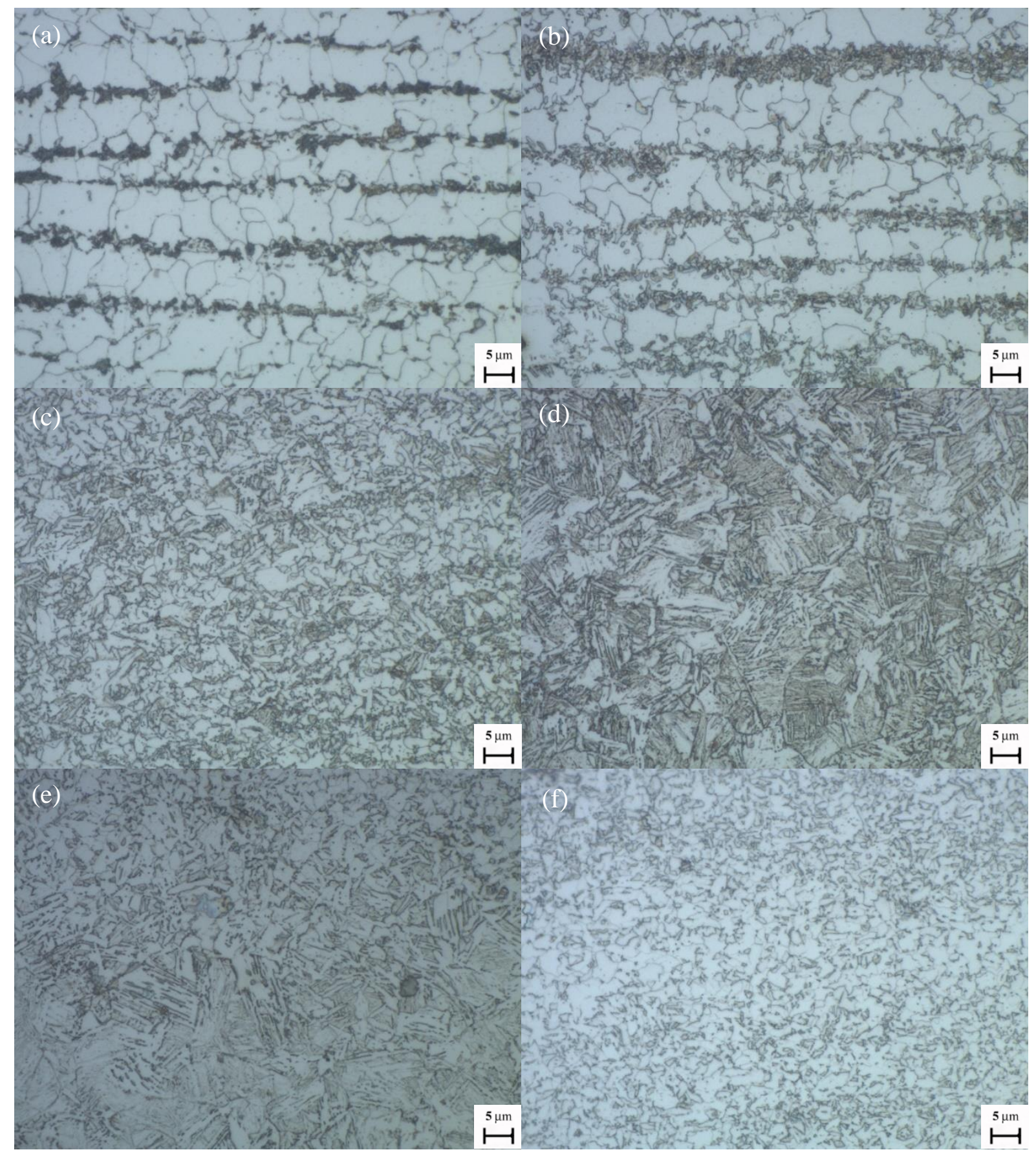

Fig. 4 Microstructure of the weld, x1000 [etched], (a) Parent material, (b) HAZ, (c) Outer TMAZ, (d) Mid TMAZ, (e) Top Surface Transition, (f) Bottom surface near weld root

This study shows that a weld of good quality has been produced with no internal defects. A refined heterogeneous microstructure was found in the TMAZ which improves mechanical properties such as strength. 


\subsubsection{Process related flaws}

A number of process related flaws were identified, the locations of which are highlighted in Fig. 5a. Close examination of the microstructure revealed intermittent top surface defects (Fig. 5b, Fig. 5c) and a continuous weld root flaw (Fig. 5d). Fig. 5b illustrates a lap defect; these are caused by insufficient fusion of the weld material and PM during the stirring process. Tool shoulder marks are visible in Fig. 5c indicating the need to optimise FSW tool materials. The darker sites observed in Fig. 5b are non-metallic inclusions. These appear near the top surface of the weld as surface oxides are drawn into the weld zone and dispersed through the material by the stirring process. This results from local plastic deformation of the steel [19].

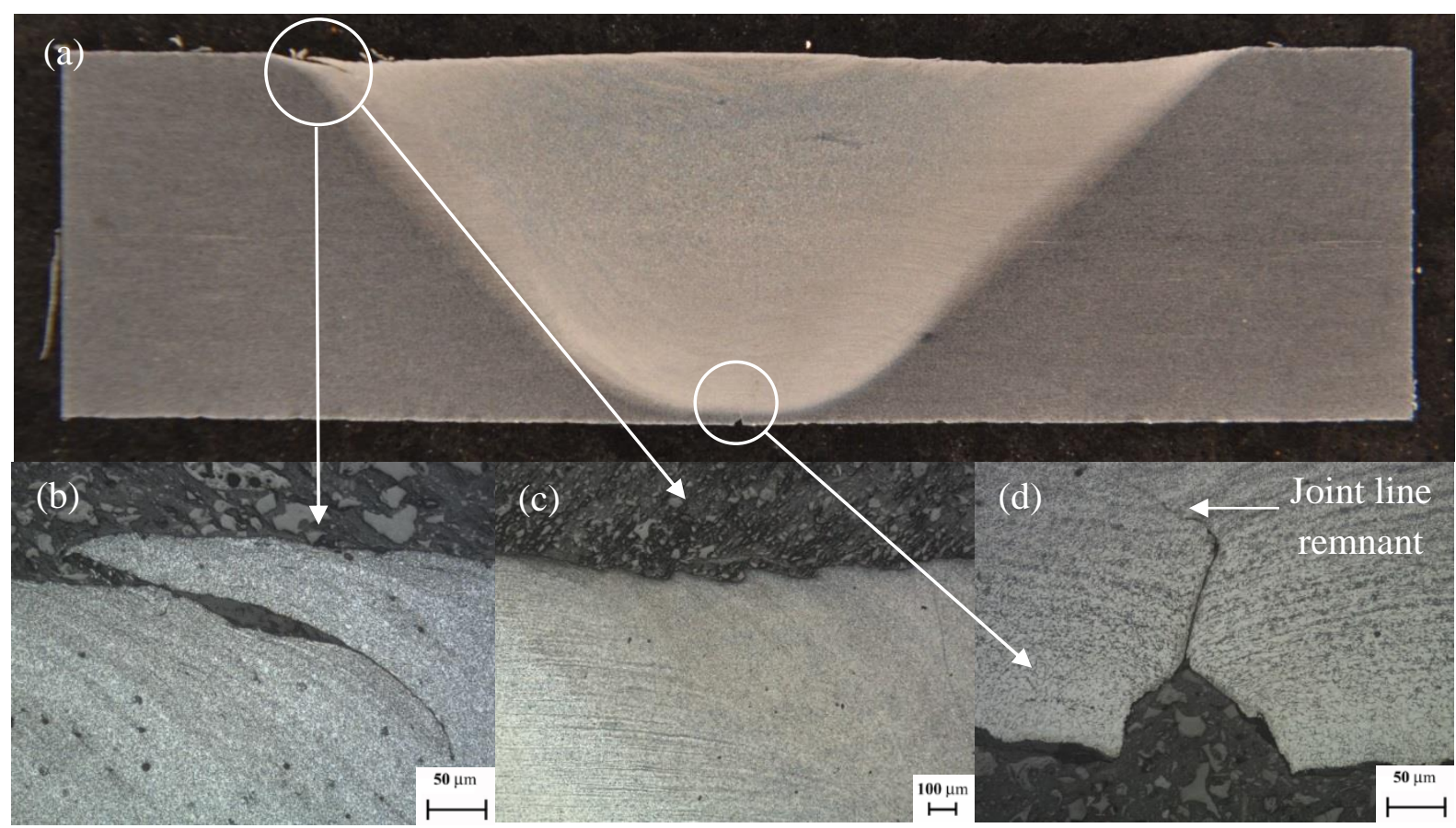

Fig. 5 Process related flaws, (a) FSW cross-section macrograph, (b) Lap defect, x200 [etched], (c) Tool shoulder marks, x100 [etched], (d) Weld root flaw, x200 [etched]

A severe notch shaped weld root flaw (Fig. 5d) was observed and this has been found to negatively affect the fatigue performance [7, 9-11]. The tip of the notch has a large stress concentration factor associated with it which can initiate cracks. The joint line remnant, a discontinuous line of oxide particles, is also visible and may offer a crack propagation route once a crack has initiated. Full penetration by the FSW tool would have prevented these flaws from developing.

\subsection{Micro-hardness measurements}

The hardness profile depicted in Fig. 6 indicates a gradual increase in hardness with increasing distance from the PM towards the weld centre; this is typical of most FSW joints. The maximum hardness was found in the centre/AD side of the TMAZ. This observation corresponds to the formation of bainite in the microstructure (Section 3.1.1). The temperature of the AD side during FSW is higher than the RT side [8] thus inducing faster cooling rates in that region. Faster cooling rates lead to the formation of harder phases such as bainite. 
Previous research [7] on FSW of DH36 steel found a maximum hardness of $302 \mathrm{HV}$ at the top $\mathrm{AD}$ side, i.e. comparable to the values recorded herein.

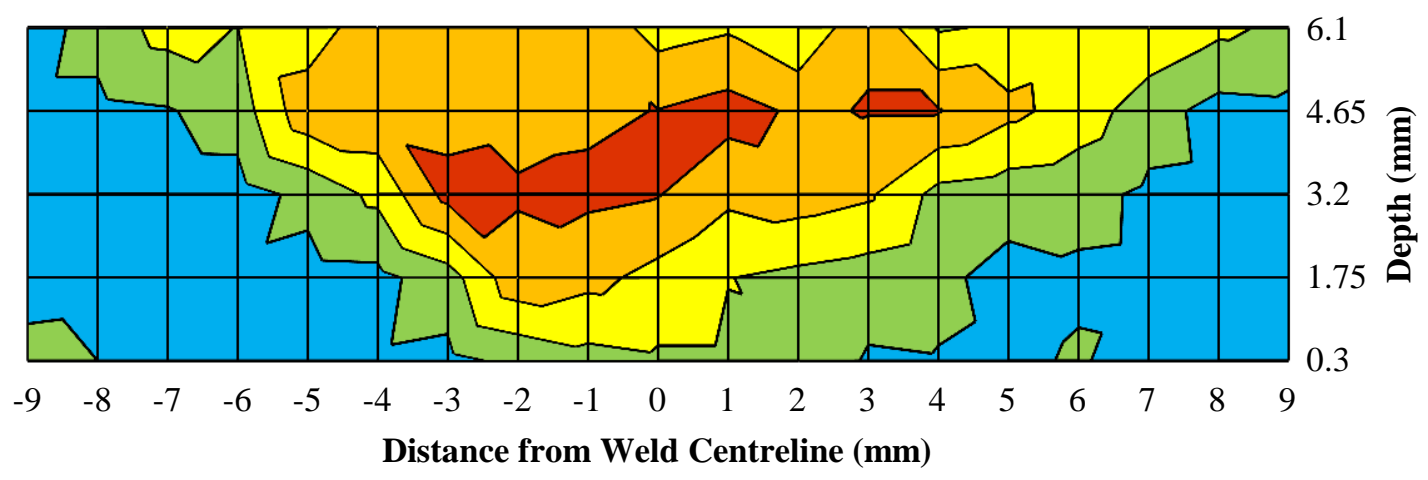

$\square 150-190 \quad \square 190-230 \quad \square 230-270 \quad \square 270-310 \quad \square 310-325$

Fig. 6 Vickers hardness distribution throughout the weld

\subsection{Transverse tensile testing results}

The reduced grain size in the welded region corresponds to an increase in yield strength. Consequently, all transverse tensile samples fractured in the PM under tensile loading. A typical image of the samples' top surface in presented in Fig. 7. Necking is clearly visible, hence indicating ductile fracture with plastic deformation of the steel. The recorded data for each tensile test are presented in Table 3.

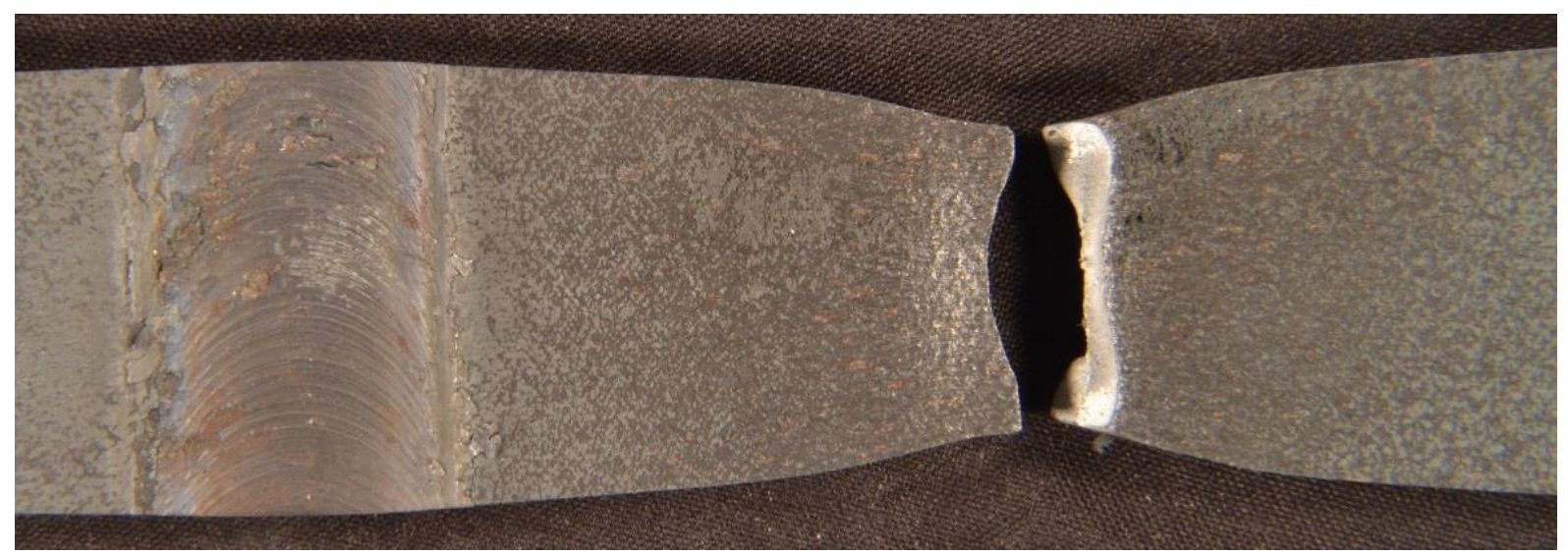

Fig. 7 Tensile sample fracture in parent material

Table 3 Tensile test results

\begin{tabular}{ccc}
\hline Specimen Number & Elastic Modulus $(\mathrm{GPa})$ & Yield Strength $(\mathrm{MPa})$ \\
\hline Tensile-1 & 220 & 406 \\
Tensile-2 & 206 & 406 \\
Tensile-3 & 202 & 401 \\
AVERAGE & 209 & 404
\end{tabular}




\subsection{Fatigue testing results}

\subsubsection{As-welded fatigue results}

The fatigue data is plotted in Fig. 8. In order to put the results into context, a comparison has been made against the recommended performance of fusion butt welds provided by the International Institute of Welding (IIW) [23]. This has been achieved by plotting the data against the most relevant fatigue class (FAT). The fatigue class indicates the characteristic stress range which results in fatigue life of $2 \cdot 10^{6}$ cycles at $97.7 \%$ survival probability. Each fatigue class is dependent on the nature of the weld. For this research, the FAT 80 line was used as this correlates to the weld examined (detail No. 214 in Ref. [23]).

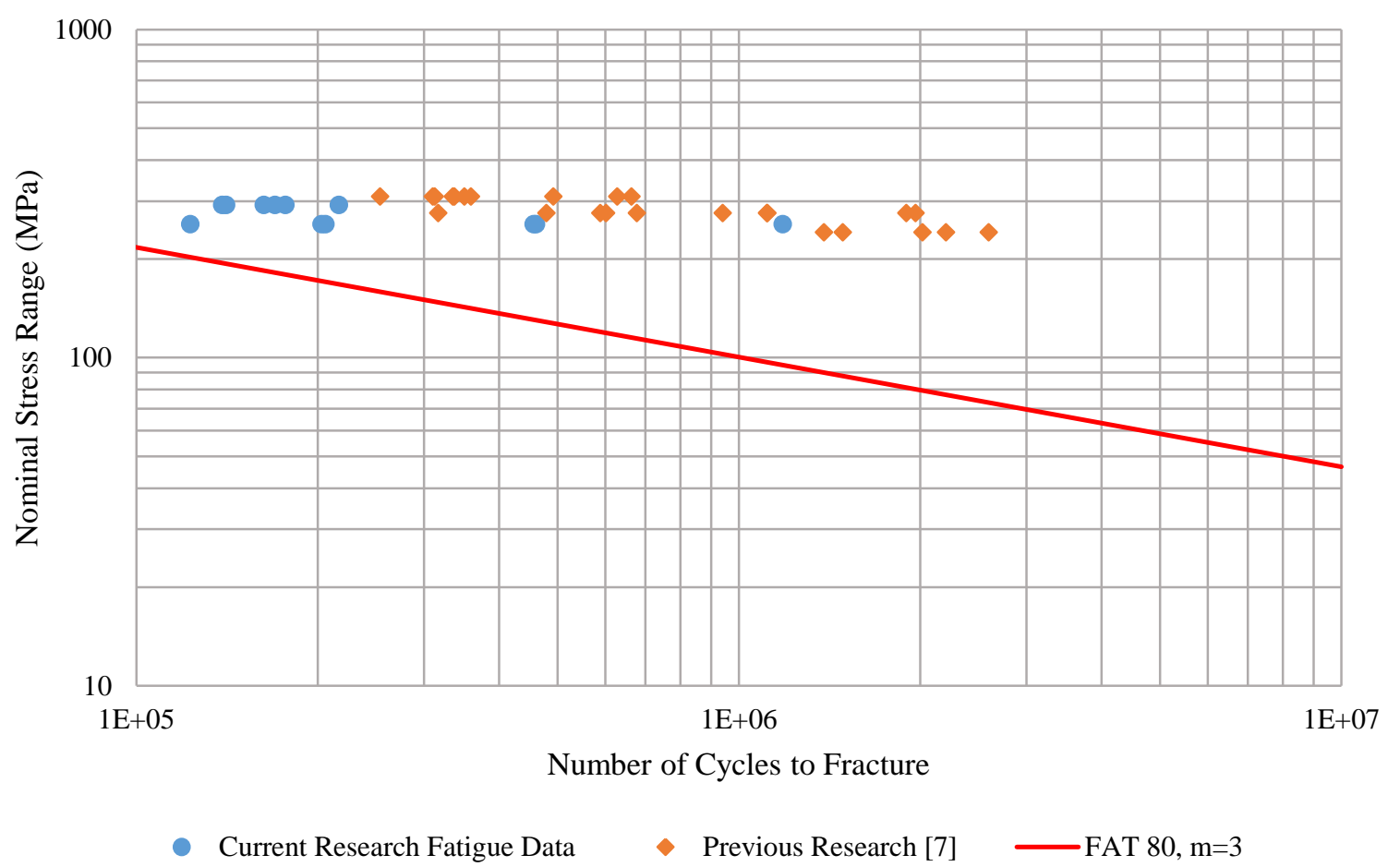

Fig. 8 Fatigue data for as-welded fatigue samples relative to FAT 80 line

Eight fatigue failures were attributed to the weld root flaw and four were linked to top surface defects. The crack initiation site for three of the latter tests was on the weld AD side and one on the RT side.

The data in Fig. 8 demonstrate inferior fatigue strength in comparison to previous FSW fatigue data on DH36 steel [7]; this is largely due to the severe weld root flaw. However, as all results are above the IIW recommendation defined by the FAT 80 line, the weld exhibits acceptable fatigue performance should it be assessed by fusion welding recommendations.

\subsubsection{Secondary bending measurements}

Table 4 summarises the secondary bending stresses calculated along with the location of fracture. The notation used here correlates with the notation in Fig. 1. 
The data reveal that the weld root is subjected to compressive stresses when clamped in the fatigue testing machine; this is in contrast to the top surface which experiences tensile stresses. The local stress at the weld root is up to $25 \%$ lower than the nominal stress applied during fatigue testing. Consequently, the weld root is tested at an artificially reduced stress range thus increasing the endurance. As shown in Section 3.4.1, the majority of failures occurred at the weld root.

Table 4 Secondary bending stresses during fatigue testing

\begin{tabular}{ccccc}
$\begin{array}{c}\text { Location of } \\
\text { Failure }\end{array}$ & $\begin{array}{c}\text { Top AD Stress } \\
(\mathrm{MPa})\end{array}$ & $\begin{array}{c}\text { Top RT Stress } \\
(\mathrm{MPa})\end{array}$ & $\begin{array}{c}\text { Bottom AD } \\
\text { Stress (MPa) }\end{array}$ & $\begin{array}{c}\text { Bottom RT } \\
\text { Stress (MPa) }\end{array}$ \\
\hline Top AD & 23.5 & 27.0 & -40.9 & -40.8 \\
Top AD & 25.6 & 27.5 & -55.0 & -51.8 \\
Weld Root & 15.9 & 2.98 & -55.9 & -35.8 \\
Weld Root & 7.70 & 16.9 & -48.3 & -60.3 \\
Top RT & 19.4 & 49.6 & -53.3 & -33.4 \\
\hline
\end{tabular}

\subsubsection{Fatigue testing of ground samples}

Due to the reduced fatigue performance in comparison to prior findings [7], two additional samples were tested having removed the top and bottom surface flaws. Removing any process related flaws allowed for the weld material itself to be tested, thus enabling a valid comparison with the as-welded samples. The depth of the weld root flaw and lap defects was measured to be $450 \mu \mathrm{m}$ and $550 \mu \mathrm{m}$ for the top and bottom surface respectively. The specimens were milled and then ground to the appropriate depth and both tested at a stress range of $80 \%$ yield strength. The results are presented in Fig. 9 along with the as-welded specimens for the equivalent stress range.

As both ground fatigue samples exceeded $2.6 \cdot 10^{6}$ cycles, the tests were terminated without fracture. Therefore, the results gathered indicate superior fatigue performance in ground samples. This highlights the detrimental effect of top surface defects and of the inadequate tool penetration on the fatigue performance of steel FSW. 


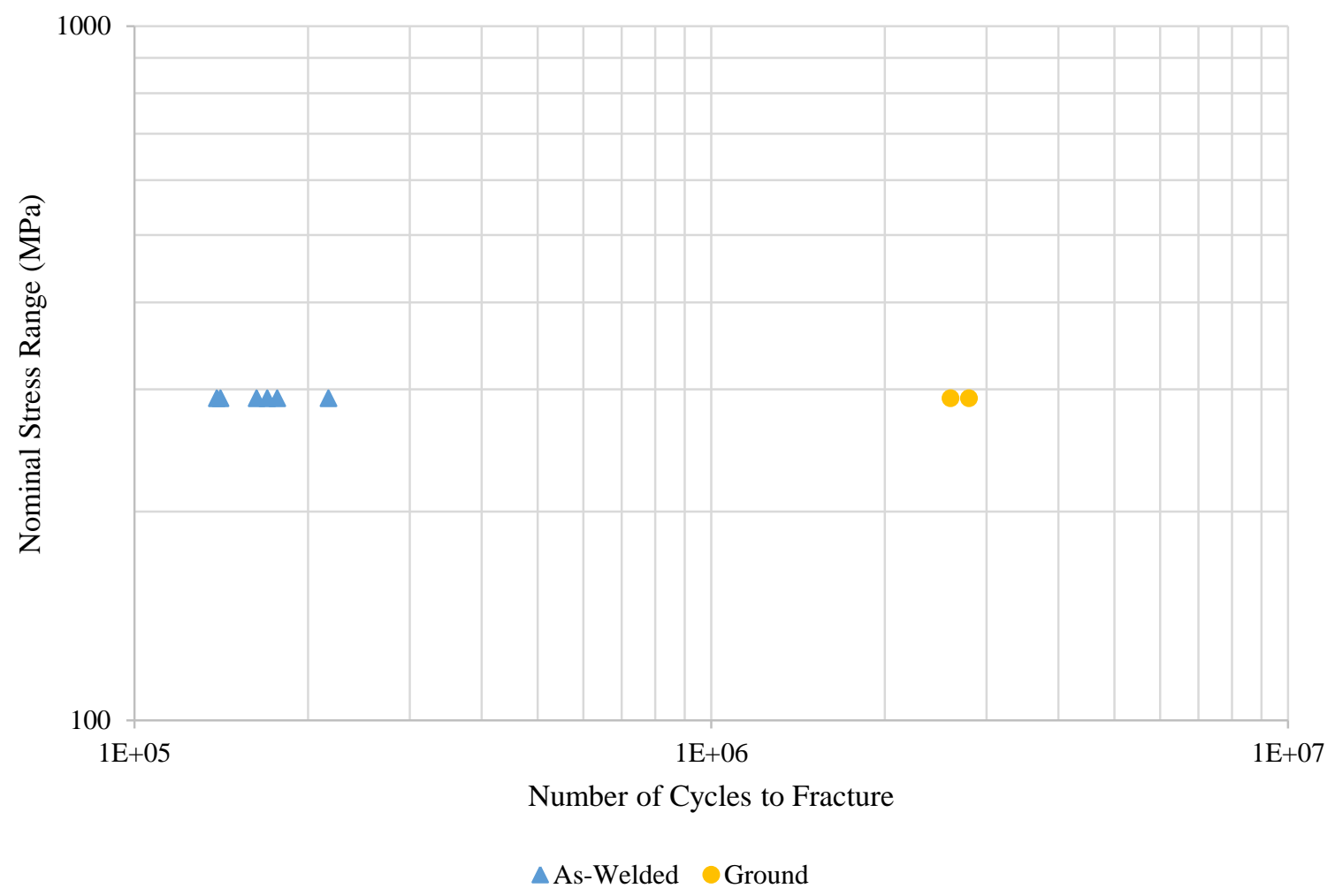

Fig. 9 Fatigue data for as-welded versus ground samples at $80 \%$ stress range

\subsection{Bend testing results}

All as-welded test specimens passed $180^{\circ}$ U-bends despite minor tearing occurring on the face in tension. These were not of sufficient magnitude to induce crack propagation. Of the six samples tested with the top and bottom surface defects ground off, only one root bend was found to fail. This was attributed to a small localised void on the bottom AD side of the weld.

\section{Discussion}

\subsection{Evaluation of as-welded fatigue failures}

Post testing analysis of fatigue samples demonstrated that the majority of cracks initiated at the weld root. Examination of the fracture surface and top surface disclosed that the crack initiated at the root and propagated through the centre of the weld (Fig. 10). The root flaw has been such that the crack has effectively been a continuation of the joint line remnant. Therefore, there have been multiple, very small, cracks formed along the weld root surface during cyclic loading. The same image also reveals a brittle fracture throughout the weld until the crack reaches the top surface, which is typical of the failure mode in steel FSW. The depth of the root flaw was found to be above the critical value previously reported [10-12] hence negatively impacting on the fatigue performance. This was further confirmed by the ground 
samples whose fatigue tests were terminated without fracture and emphasises the need to ensure full penetration FSW in practice.

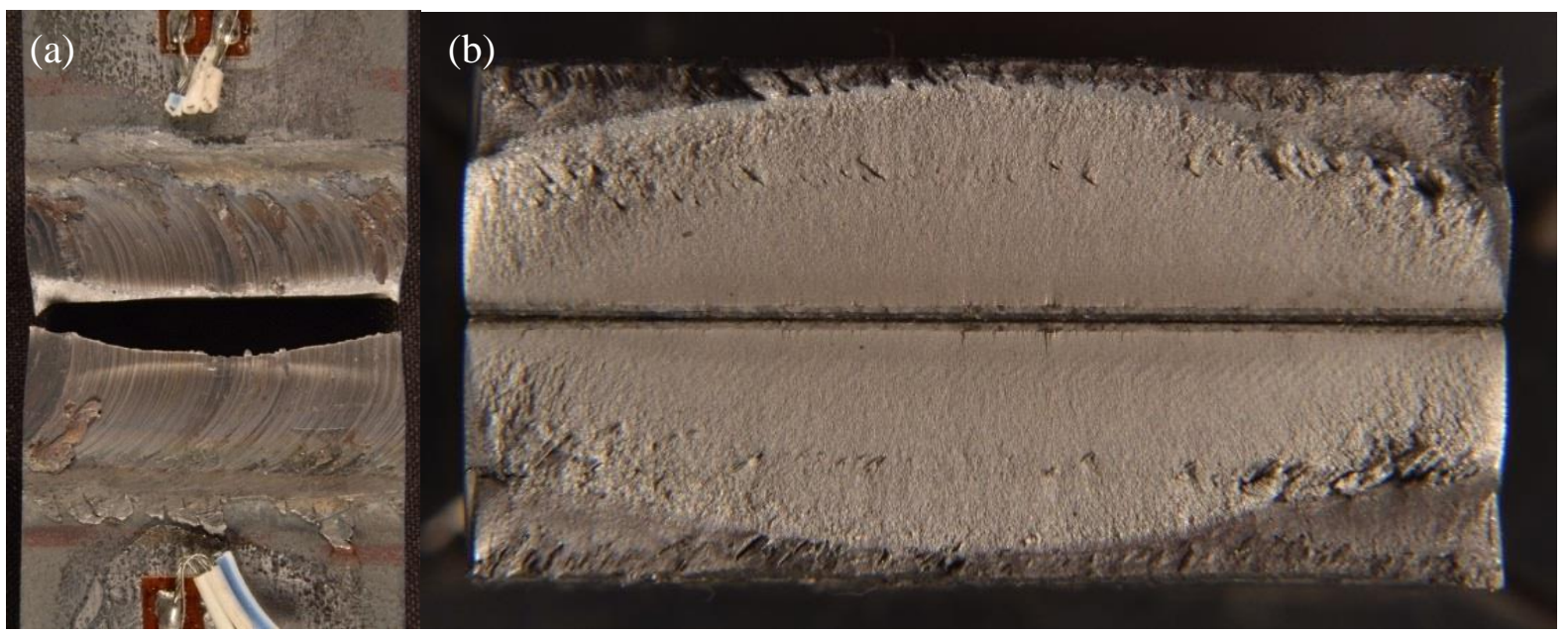

Fig. 10 Fatigue failure due to weld root flaw, (a) Top surface, (b) Fracture surface

Specimens machined from one weld section were found to fail on the AD side of the weld zone. Examination of the microstructure revealed an incomplete fusion path as shown in Fig. 5b. In addition to this, one sample was found to fail due to the tool shoulder marks as illustrated in Fig. 5c. The thin elongated nature of the defect (Fig. 5b) assisted in the propagation of the crack. The uneven top surface profile generated by the tool shoulder (Fig. 5c) provides multiple potential crack initiation sites, hence explaining the specimen's failure at this location instead of the weld root. Top and bottom surface macrographs shown in Fig. 11 illustrate that the crack initiated on the top surface and progressed through the PM rather than follow the profile of the weld. The PM has been previously found to have lower crack resistance than the friction stir weld $[13,14]$, which is in agreement with the findings presented herein.

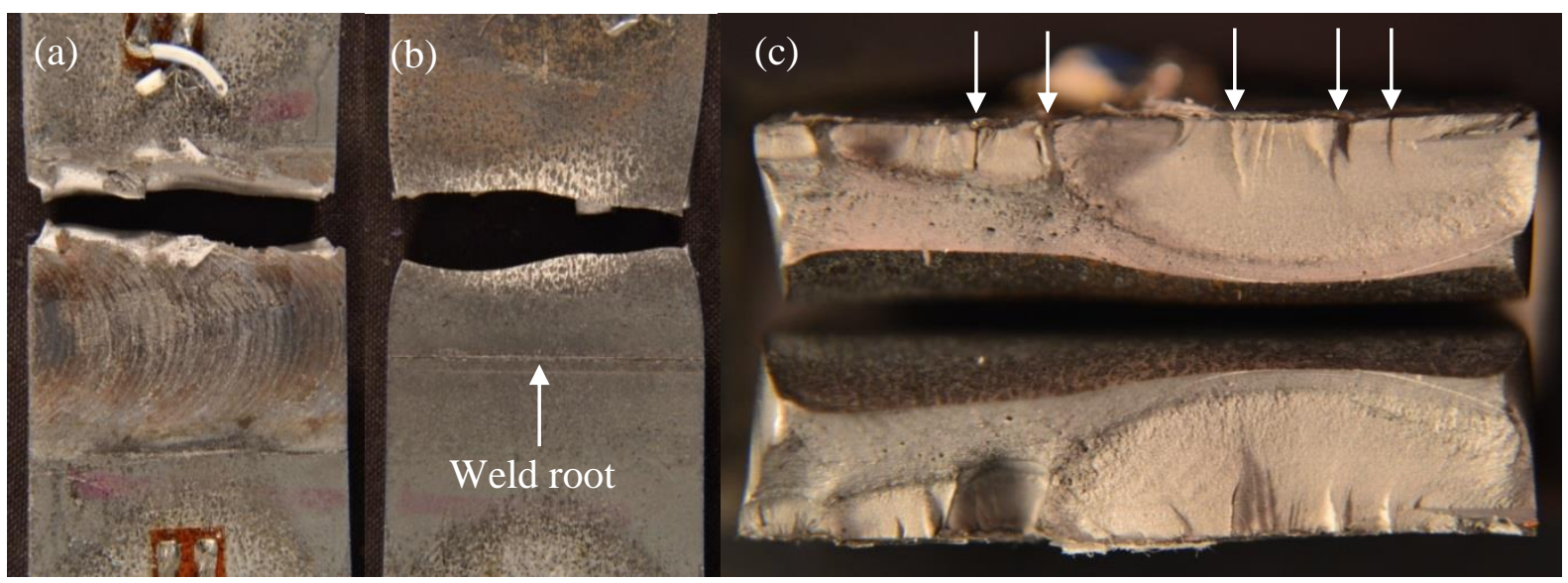

Fig. 11 AD side fatigue failure, (a) Top surface, (b) Bottom surface, (c) Fracture surface with highlighted crack propagation sites

The fracture surface (Fig. 11c) reveals multiple crack initiation sites on the top surface, as indicated by the arrows. As the crack propagates through the parent material, there is significant plastic deformation at the bottom surface and subsequent necking. This has 
occurred because the parent material is softer and more ductile than the weld region as reported in the micro-hardness measurements. Small non-metallic inclusions exist as voids on the fracture surface which have been pulled by the necking of the parent material.

The depth of the weld root flaw and lap defects was measured in order to determine the ratio at which the lap defect became the dominant failure location. The critical ratio of lap defect depth to weld root depth was found to be 4:5 for top surface failure. Although secondary bending measurements indicated that the top surface should have been the dominant fracture region (due to higher tensile stresses), the weld root was found to be the critical crack initiation site.

Defect free welds of refined microstructure were produced but the inclusion of process related flaws reduced the fatigue life. This emphasises the need for continuous improvement of FSW tool design and material so that such features can be prevented. Optimisation of the welding parameters is also required [7].

\subsection{Evaluation of bend testing}

Fig. 12 shows two tested bend specimens, one as-welded root bend and one as-welded face bend. For the face bends (Fig. 12a), tearing was found to form along the swirl pattern left by the FSW tool but not to a detrimental effect. In the root bend (Fig. 12b), it is clear that the load exerted on the weld root has pulled it apart; however, the crack has not propagated through the weld as seen in the fatigue testing. Examination of the microstructure post testing further confirmed this observation, as the root flaw depth was found to be effectively equivalent to that prior to testing. Fig. $12 \mathrm{~b}$ also denotes that there is very little deformation of the weld in comparison with the PM due to the increased hardness in the weld material.

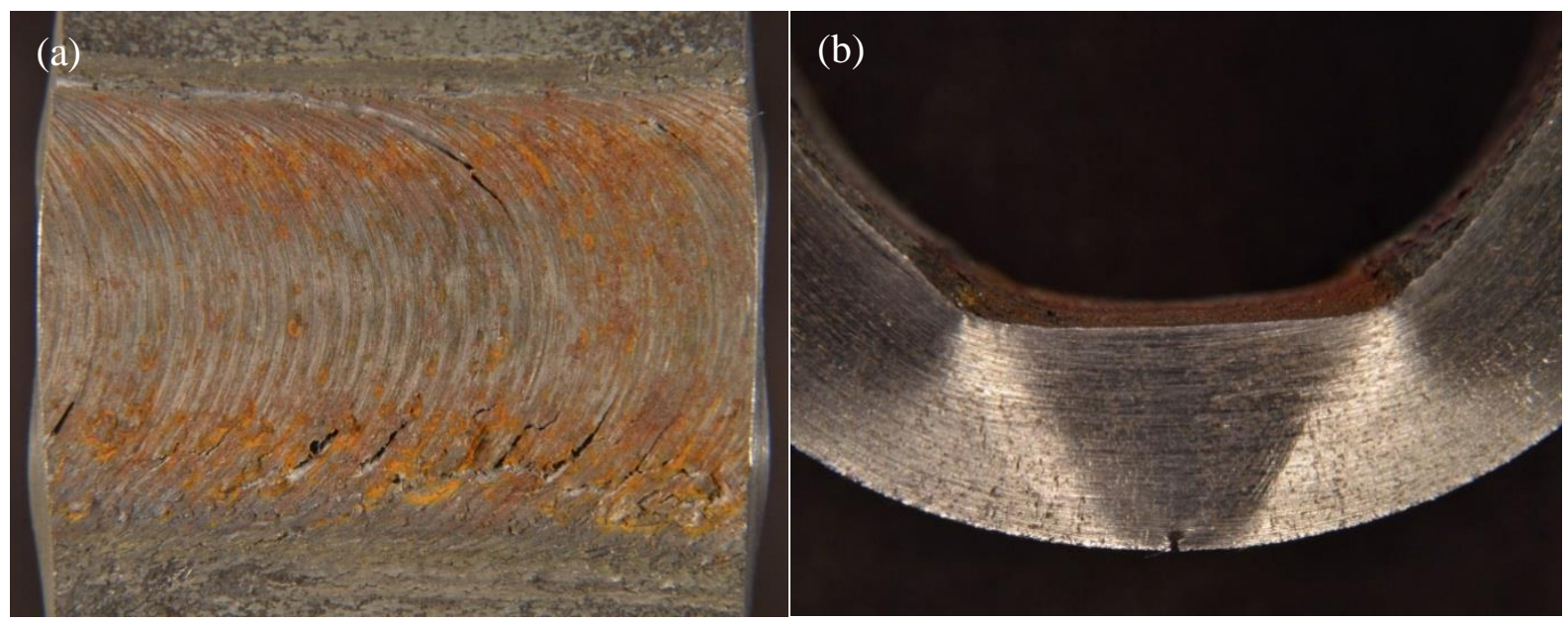

Fig. 12 As-welded bend test specimens, (a) Face bend top surface, (b) Root bend side

Bend testing exhibits that satisfactory levels of impact toughness were achieved as the surface defects present did not propagate to detrimental effect. Prior research [8] indicated that the impact toughness of various FSW DH36 plates increased from the RT side to a maximum at the inner TMAZ on the AD side. This provides a reason for the more tearing which was found to occur on the RT side of face bends and for the weld root flaw not propagating in root bends. 
Solely one specimen was observed to fail in the bend testing programme; Fig. 13a and b depict the bottom surface and fracture surface respectively. Fracture did not propagate through the entire sample and subsequent examination revealed that the crack originated from the bottom AD side of the weld. There are two different serration patterns observed with a definitive dividing line highlighted by the arrows (Fig. 13b). This indicates that fracture has initiated at an internal defect and propagated towards the top and bottom surface. The serration pattern is caused by the FSW tool, showing that the material was mechanically worked rather that thermo-mechanically stirred. A similar fracture was observed in previous research [8].

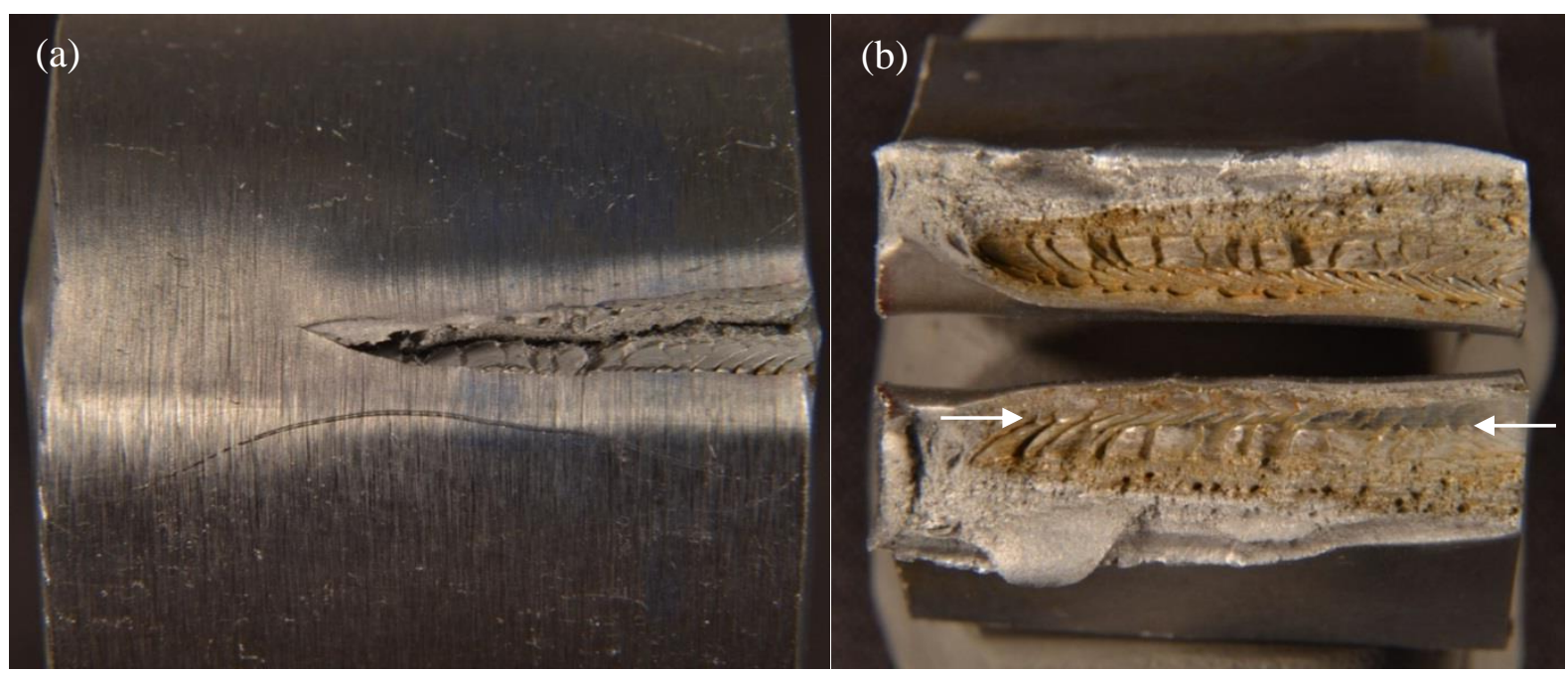

Fig. 13 Ground root bend test fracture, (a) Bottom surface, (b) Fracture surface

No defects were noted upon examination of the section that did not fracture (left hand side of Fig. 13a), therefore the cavity which caused this fracture occurred in a localised region of the welded plate.

\section{Conclusions}

A comprehensive fatigue and bending programme has been implemented to assess FSW of DH36 steel subjected to these loading conditions. These testing programmes were complemented by microstructural characterisation, micro-hardness measurements and transverse tensile testing. The following conclusions are drawn from this study:

1. Defect free welds consisting of a highly refined microstructure were identified. In all cases, these consisted of a heterogeneous microstructure in the TMAZ and minimal grain growth in the HAZ.

2. Micro-hardness measurements demonstrated that the hardest region in the weld was located in the centre/AD side of the TMAZ (323 HV) which correlated with the formation of bainite in this region.

3. Fatigue performance was poor when considered against comparable friction stir welds in DH36 plate. However, the fatigue strength was found to exceed the existing international recommendations for single sided fusion butt welds. 
4. Significant improvement in fatigue life was observed in ground samples since these tests were terminated without fracture after $2.6 \cdot 10^{6}$ cycles. This indicates that process related features such as the weld root flaw have a negative impact on fatigue performance, therefore need to be dealt with.

5. Secondary bending measurements indicated that the local stress at the weld root was up to $25 \%$ lower than the nominal stress determined prior to fatigue testing, thus artificially improving fatigue performance.

6. FSW DH36 steel performed well in bend testing with only one failure in twelve tests; the latter was attributed to a localised internal defect. Despite the presence of surface flaws, cracks did not propagate through the weld which offered a strong indication about highly satisfactory toughness within the TMAZ.

Overall, this research has proved that the FSW process is capable of producing steel welds of high quality. However, process related flaws on the top and bottom surface of the weld have reduced the fatigue life. Despite this, the welds display satisfactory fatigue performance when compared to class rules for corresponding fusion welding. Such findings emphasise the importance of ongoing tool improvement and optimisation of welding parameters.

\section{Acknowledgements}

The authors would like to acknowledge the financial support of the European Union which has funded this work as part of the Collaborative Research Project HILDA (High Integrity Low Distortion Assembly) through the Seventh Framework Programme (SCP2-GA-2012314534-HILDA).

\section{References}

1. Dehghani K, Ghorbani R, Soltanipoor a. R (2014) Microstructural evolution and mechanical properties during the friction stir welding of 7075-O aluminum alloy. Int J Adv Manuf Technol 77:1671-1679. doi: 10.1007/s00170-014-6574-0

2. Padmanaban G, Balasubramanian V (2010) An experimental investigation on friction stir welding of AZ31B magnesium alloy. Int J Adv Manuf Technol 49:111-121. doi: 10.1007/s00170-009-2368-1

3. Ramulu PJ, Narayanan RG, Kailas SV, Reddy J (2013) Internal defect and process parameter analysis during friction stir welding of Al 6061 sheets. Int J Adv Manuf Technol 65:1515-1528. doi: 10.1007/s00170-012-4276-Z

4. Rajakumar S, Razalrose A, Balasubramanian V (2013) Friction stir welding of AZ61A magnesium alloy: A parametric study. Int J Adv Manuf Technol 68:277-292. doi: 10.1007/s00170-013-4728-0

5. Lienert T, Stellwag W, Grimmett B, Warke R (2003) Friction stir welding studies on mild steel. Weld J Res Suppl 1-9. 
6. McPherson N, Galloway A, Cater SR, Hambling SJ (2013) Friction stir welding of thin DH36 steel plate. Sci Technol Weld Join 18:441-450. doi:

10.1179/1362171813Y.0000000122

7. Toumpis A, Galloway A, Molter L, Polezhayeva H (2015) Systematic investigation of the fatigue performance of a friction stir welded low alloy steel. Mater Des 80:116-128. doi: 10.1016/j.matdes.2015.04.046

8. Toumpis A, Galloway A, Cater S, McPherson N (2014) Development of a process envelope for friction stir welding of DH36 steel - A step change. Mater Des 62:64-75. doi: 10.1016/j.matdes.2014.04.066

9. Azevedo J, Infante V, Quintino L, dos Santos J (2014) Fatigue Behaviour of Friction Stir Welded Steel Joints. Adv Mater Res 891-892:1488-1493. doi: 10.4028/www.scientific.net/AMR.891-892.1488

10. Dickerson TL, Przydatek J (2003) Fatigue of friction stir welds in aluminium alloys that contain root flaws. Int J Fatigue 25:1399-1409. doi: 10.1016/S0142-1123(03)00060-4

11. Kadlec M, Růžek R, Nováková L (2015) Mechanical behaviour of AA 7475 friction stir welds with the kissing bond defect. Int J Fatigue 74:7-19. doi:

10.1016/j.ijfatigue.2014.12.011

12. Zhou C, Yang X, Luan G (2006) Effect of root flaws on the fatigue property of friction stir welds in 2024-T3 aluminum alloys. Mater Sci Eng A 418:155-160. doi: 10.1016/j.msea.2005.11.042

13. Lakshminarayanan AK, Balasubramanian V (2012) Assessment of fatigue life and crack growth resistance of friction stir welded AISI 409M ferritic stainless steel joints. Mater Sci Eng A 539:143-153. doi: 10.1016/j.msea.2012.01.071

14. Pandey KN, Gupta SK (2013) Fatigue Crack Growth Analysis of Mild Steel Plate Welded by Friction Stir Welding. ASME 2013 Int. Mech. Eng. Congr. Expo. San Diego, California, USA.

15. Mahoney M, Sanderson S, Feng Z, et al. (2013) Friction Stir Welding of Pipeline Steels. In: Mishra RS, Mahoney M, Sato Y, et al. (eds) Frict. Stir Weld. Process. VII. Wiley, Hoboken, NJ, pp 59-69.

16. Thomas WM, Threadgill PL, Nicholas ED (1999) Feasibility of friction stir welding steel. Sci Technol Weld Join 4:365-372. doi: 10.1179/136217199101538012

17. Allart M, Benoit A, Paillard P, et al. (2014) Metallurgical Study of Friction Stir Welded High Strength Steels for Shipbuilding. Mater Sci Forum 783-786:2798-2803. doi: 10.4028/www.scientific.net/MSF.783-786.2798

18. Reynolds AP, Tang W, Posada M, Deloach J (2003) Friction stir welding of DH36 steel. Sci Technol Weld Join 8:455-460. doi: 10.1179/136217103225009125 
19. Barnes SJ, Bhatti AR, Steuwer A, et al. (2012) Friction stir welding in HSLA-65 steel: Part I. Influence of weld speed and tool material on microstructural development. Metall Mater Trans A Phys Metall Mater Sci 43:2342-2355. doi: 10.1007/s11661-012-1110-z

20. British Standards Institution (2009) BS EN ISO 6892-1:2009, Metallic materials Tensile testing Part 1 : Method of test at ambient temperature.

21. British Strandards Institution (2006) BS 7270:2006, Metallic materials - Constant amplitude strain controlled axial fatigue - Method of test.

22. British Standards Institution (2011) BS EN ISO 5173:2010 +A1:2001, Destructive tests on welds in metallic materials - Bend tests.

23. Hobbacher A (2008) Recommendations for fatigue design of welded joints and components. International Institute of Welding, doc. XIII-2151r4-07/XV-1254r4-07. 